\title{
When Local Meets Global: Non-academic Factors Affecting International Medical Education in Grenada, West Indies
}

\author{
Lauren Orlando, Emily Harms, Heather Brathwaite, Jill Paterson, Glen Jacobs \\ Department of Educational Services, St. George's University, Grenada, West Indies
}

\begin{abstract}
The purpose of the study was to investigate the non-academic challenges for Grenadian students who are a minority at an international university (St. George's University) in their own country, and how these non-academic challenges have changed in the past 17 years. All 36 Grenadian students enrolled in the two years of basic sciences in the School of Medicine were invited to participate in an optional, anonymous survey, which gathered demographic information and information regarding nonacademic factors that students' perceived affected their studies. Questions in the descriptive survey included open-ended, Likert scale, ranking, and multiple choice questions. Twenty-four of the 36 students (67\%) responded to the questionnaire. Three major issues were identified. Ten students $(n=21,48 \%)$ ranked housing as the number one problem for them. Sixteen participants $(n=21,71 \%)$ have financial difficulties, which makes it difficult to afford on-campus or even off-campus housing. Traveling to and from campus was a problem for 17 students $(n=21,76 \%)$, who stated it was time consuming. Transportation, housing, and financial issues still pose a challenge for Grenadian students. In fact, housing opportunities have become more limited in the past 17 years. The challenges could be lessened if Grenadian students were guaranteed oncampus housing and if the government scholarship provided a small living stipend.
\end{abstract}

\section{Introduction}

For many aspiring medical doctors in the United States (US), offshore or international medical schools (OMSs) are the most viable choice. As the need for trained medical professionals has increased in the US, so too has the enrollment in OMSs in the Caribbean. Eckhert [1] states that international medical graduates (IMGs) comprise $25 \%$ of the physicians in the US workforce. In 2005, 27\% of practicing IMGs in the

United States were US citizens, which demonstrates that a growing number of students are choosing an alternative and non-traditional method of training [2]. In 2013, there were approximately 39 for-profit OMSs located in the Caribbean, with a student population that is predominantly students from the US [2]. The most prominent of these Caribbean institutions are found in Grenada, Dominica, Antigua and Barbuda, and Sint Maarten. The predominant issues facing OMSs are the accreditation process and standards, student loan financing, retention rates, clinical rotation spots, United States Medical Licensing Examination (USMLE) pass scores, and ultimately, residency matching placements. In the 2013 residency matching outcomes, Grenada produced the highest number of applicants in the Caribbean who matched for US residency spots, both US IMGs and non-US IMGs [3].

St. George's University (SGU), the only medical school located on the island of Grenada, has played a pivotal role for promising medical students since it was established in 1976. There are currently over 15,000 graduates of SGU, with a faculty and student body from over 140 countries, and more than 70 affiliated clinical hospitals in the US and the United Kingdom [4]. SGU currently includes four different schools: School of Medicine (SOM), School of Veterinary Medicine, School of Graduate Studies and School of Arts and Sciences (SAS). For the purposes of this paper, our focus will be on the SOM Grenadian students enrolled at SGU. In an email correspondence a representative from the SGU Registrar's Office noted that as of October 2015, the SOM had a total enrollment of approximately 4,440 students with only 36 Grenadian students (N. Baksh, personal communication, November 19, 2015).

\section{Support Services for SGU Students}

It is essential for medical students to actively learn lecture and lab content and not simply regurgitate what professors include in course notes and resources. One way to help students process material and tackle multiple choice questions, for example, is through small group learning. The 
Department of Educational Services (DES) at SGU promotes small group learning as a fundamental active learning tool for all four schools, providing student assistance with learning strategies, active learning tools, examination taking skills, supplemental learning review groups led by faculty members, and review groups and small group tutorials led by upper term students. DES provides workshops on various study skills for all three schools, including the SAS from which 21 out of the 24 Grenadian SOM students matriculated.

DES, in collaboration with the SAS Writing Centre, offers SAS students workshops in time and task management, note taking skills, test taking and test anxiety, and multiple-choice questions, among others. In addition to DES led workshops and oneonone learning strategy appointments, students can also be trained as small group facilitators to assist lower term students in specific courses. According to Ross and Cameron [5], although peer teachers are not experts, peer-teaching in small group sessions is beneficial for both the teachers and learners. DES focuses on group learning as it encourages students to learn from their colleagues to truly understand the high-yield processing of content rather than pure memorization. Santee and Garavalia [6] found that when peer-teacher programs were added to the curriculum, they improved students' academic performance and maintained institutional academic success.

Whether review groups are formally or informally organized, it is crucial for medical students to function well in a collaborative learning environment as this will be the predominant method used in clinical rotations and residencies. Meo [7] highlights how these small group teaching and learning sessions allow students to transfer new ideas, and increase retention and critical analysis of concepts. This form of active learning increases student interest and develops communication skills and teamwork ability. Students are able to share learning strategies and tools with one another as they are encouraged to self-test the content and ensure their processing is matches course expectations. This self-directed and regulated learning encompasses all the necessities to facilitate content moving from short term memory into long term retention. These small group learning interactions boost student involvement and integration as they foster teamwork, time and task management, and higher-order processes such as analysis, evaluation, and synthesis.

\section{Context and Rationale}

Grenada has one of the highest unemployment rates in the Caribbean, ranging between 29-50\%, depending on the age group. As a developing country, the gross national income in Grenada is approximately $\$ 7,842$ US per year, which alludes to the standard of living and the potential challenges it poses for Grenadian students at SGU [8]. Scholarships and tuition reduction are available for all Grenadian students in the SAS; however, there are only ten scholarships available for Grenadian SOM students, once per year, in the Spring term, beginning in January. The scholarship supports students throughout their two years of Basic Sciences and two clinical years abroad. Every January, 10 additional scholarships are awarded. Because the majority of Grenadian students and their families would not be able to afford the high cost of tuition on their own, the number of available scholarships drastically limits the intake of Grenadian students in the SOM.

Grenadian students, therefore, despite being in their home country, are a minority in this international medical school that serves a student population who are largely from the US. While the dynamics and nonacademic issues for Grenadian SOM students vary, the majority of these local students have very similar perceived barriers to their academic success, as do foreign students at SGU. Jacobs' study on nonacademic factors affecting student success at SGU highlights some of these perceived barriers [9]. Our current study therefore offers insight to help address some of the nonacademic constraints encountered by local students at an international medical school. These nonacademic issues have an impact beyond SGU as the same issues may affect other local students and IMGS in the Caribbean and surrounding regions. An optional, anonymous survey was sent to all Grenadian SOM students who were enrolled in terms one through five at SGU in the Basic Science years in the fall of 2015. The rationale for the survey was to assess the challenges for local students in order find ways to improve their academic success at SGU. Our research therefore focuses on three primary areas: 1 . What are the non-academic challenges for Grenadian SOM students at SGU? 2. How have the non-academic factors affecting the success of Grenadian SOM students changed in the past 17 years? 3. What support is needed for Grenadian SOM students at SGU?

\section{Brief Literature Review}

The academic success of students at the tertiary level involves both academic and non-academic factors. To provide a quality education, institutions must encourage students' growth and development in both of these areas [10]. As far back as the 1950s, educators have recognised that the rate of student success is strongly correlated with a number of nonacademic issues. Tracey and Sedlacek [11] identified a number of non-academic variables that determine the success of non-traditional students at 
tertiary level institutions. Some of these variables, particularly positive self-concept or confidence, availability of strong support person, and knowledge acquired in a field, are applicable to the current study.

Sedlacek developed a non-academic questionnaire from these variables to be used in admissions and student advancement [12]. Although Thomas, Kuncel, and Credé [13] found that the questionnaire could not accurately predict student success and should not be used to determine university admission, the questionnaire suits our purpose, which is to measure student perception.

According to Nagaoka et al. [14], there are five non-academic factors that are associated with academic performance: mindsets, learning strategies, social skills, perseverance, and academic behaviors. Students' attitudes towards their studies, along with their academic preparedness, correlate with their success at the tertiary level. The initiatives they take and strategies they employ to enhance learning can directly impact the rate of success, as well. Nagaoka et al. [14] found that students show more dedication to their studies if they have positive academic mindsets. Duckworth, Peterson, Matthews, and Kelly [15] identify perseverance as a key personality trait in determining students' academic success, which they define as grit. They state that academic perseverance indicates whether a student is able to concentrate and stay engaged in the work, even though there are obstacles, setbacks and distractions. A sense of belonging to a community is also an important factor for academic success; educational theory indicates that interaction with others improves understanding and better facilitates learning [15]. Hayes et al. [16] also acknowledge that local medical students at an international university in their own country may encounter cultural and academic obstacles. Grenadian medical students face a similar situation as SGU is a US medical school.

The factors for student academic success go far beyond the walls of the school. According to Win and Miller [17], domestic environment and parents' level of education significantly affect students' performance. Jacobs [9] builds on this idea with his evaluation of student academic performance at a university in Grenada. He further identifies housing and transportation, financial support, individual personalities, emotional support, and cultural issues as major determinants of student success. Lack of financial support, for example, leads to worry and stress for students. Additionally, the poor transportation system and long commutes to and from school further add to the stress. Jacobs' study offered a number of recommendations for improving the academic environment for students. For example, he suggests that the institution should reconsider current policies and assist students on scholarships with additional funding to cover their day-to-day needs. This has been the only study thus far on factors affecting academic success at SGU.

Our research focused on the Fall 2015 cohort of Grenadian students at SGU to determine the nonacademic factors affecting their academic success. We investigated the core challenges Grenadian students face, given that they are a minority at an international university in their country. These factors are measured against Jacobs' study to assess how the issues have, or have not, changed in the past 17 years. We acknowledge the need to address the matter and offer recommendations for targeting specific areas for the academic success of Grenadian students.

\section{Methods}

This study was conducted to assess the nonacademic factors influencing the academic success of Grenadian SOM students at an international medical school in Grenada, and how these factors have changed since 1999. Our study follows up on Jacobs' 1999 study, in which Jacobs collected data on the Grenadian students attending the SOM using the "Supplementary Admissions Questionnaire" [12] and open interviews. Jacobs' grounded theory study design allowed students to identify their own nonacademic factors, instead of being guided towards them [9].

We chose a descriptive research design for our follow-up study to understand our target population's perceptions and opinions about the non-academic factors influencing their academic success. This research design allowed us to collect both quantitative and qualitative data while protecting the anonymity of participants. The study was approved by the IRB office at St. George's University. Our survey was based on the "Supplementary Admissions Questionnaire" [12], which was originally designed as a tool to measure nonacademic characteristics to help in admissions decisions. We chose this measure in large part for consistency because it was the same established measure used in Jacobs' 1999 study. However, we adapted this measure to more closely align with our research questions. Whereas Jacobs used the survey as a starting point for open-ended interviews, we chose to use the survey as the only instrument. Validity on our modified survey was established by getting feedback from colleagues and the original researcher on the content, wording, and order of survey questions. We also conducted a pilot study by administering the survey to colleagues to further establish validity.

The study participants were Grenadian medical students enrolled in the SOM at SGU. They all selfidentified as Grenadian, having listed Grenadian as their nationality on their registration paperwork. Due to the small number of Grenadians enrolled in 
the medical school, we used census sampling and invited all 36 Grenadian students enrolled in the Fall 2015 term to participate in the survey.

Our target population received an email with a request to participate and a link to the online survey. The first question of the survey was the choice to provide informed consent. If students did not provide consent, they could not access the remainder of the survey. The informed consent form stated that all responses were anonymous. The survey was open for two weeks, and the email invitation was sent out three times to remind students to participate. Survey questions asked about demographics, study partners, issues impacting students' ability to join group study sessions, perceived level of preparation for medical school, support structures, and the impact that housing, finances, and transportation have on their studies.

Quantitative survey results were analyzed using descriptive statistics, and qualitative responses were independently reviewed by all members of the research team and coded for patterns. As a team, we discussed the patterns and clarified our findings.

\section{Results}

Of the 24 students responding to the survey, 21 students either matriculated from the Biology Department of the SAS or through the Pre-Medical Sciences Program at St. George's University. One of the 24 students (4\%) was not on a full-tuition scholarship from the Government of Grenada. Students were asked which of the following nonschool related activities were important parts of their lives $(\mathrm{n}=21)$ : church (15 students, $71 \%)$, family obligations (11 students, 52\%), sports (8 students, $38 \%)$, volunteer work (8 students, $38 \%)$, extracurricular activities (5 students, 24\%), community involvement (3 students, 14\%), none (1 student, 5\%), and job (0\%). Fifteen participants $(n=21,71 \%)$ reported that non-school related activities did not infringe on time for studies. Five students $(\mathrm{n}=21,24 \%)$ felt those activities sometimes made it challenging and one participant $(n=21,5 \%)$ found it challenging to find time for studies along with the non-school related activities. Two students $(\mathrm{n}=21,10 \%)$ reported having no access to internet at home, with one student $(\mathrm{n}=21,5 \%)$ having only intermittent access to it at home. Because university students sometimes leave school before receiving a degree, students were asked what would likely cause should this happen to them. Fifteen students $(n=23$, $65 \%$ ) were absolutely certain they would obtain a degree and nine students $(n=23,39 \%)$ reported that lack of family finances would be the reason for dropping out of school. Students did not attribute withdrawal from school to lack of academic ability or insufficient reading and study skills. Nineteen students $(n=21,90 \%)$ reported having a person or system to turn to for support. Seventeen students $(n=21,81 \%)$ also felt that their families encouraged them to attend university. Only eight $(n=24,33 \%)$ students' mothers and seven $(n=24,29 \%)$ students' fathers held a bachelor's degree or higher.

When asked if participants felt as skilled academically as the average applicant to SGU, 8 participants $(\mathrm{n}=21,38 \%)$ strongly agreed, 11 participants $(\mathrm{n}=21,52 \%)$ agreed, 2 participants $(\mathrm{n}=21,10 \%)$ disagreed and $0 \quad(0 \%)$ strongly disagreed. Seven participants $(n=21,33 \%)$ strongly agreed that they are as academically prepared as the average applicant to SGU: 12 participants $(n=21$, $57.14 \%)$ agreed, 2 participants $(\mathrm{n}=21,10 \%)$ disagreed, and 0 participants $(0 \%)$ strongly disagreed. When asked if they expected to have a harder time than most students at SGU, 3 participants $(\mathrm{n}=21,14 \%)$ strongly agreed, 6 participants $(\mathrm{n}=21$, $29 \%)$ agreed, 10 participants $(n=21,48 \%)$ disagreed, and 2 participants $(\mathrm{n}=21,10 \%)$ strongly disagreed. Thirteen participants $(n=20,65 \%)$ think the time it takes to get to campus negatively affects their ability to meet others to study. Twelve participants $(n=21$, $57 \%$ ) believe the time it takes to get to campus negatively affects their ability to attend DES sessions. Fourteen students $(n=21,67 \%)$ agree that they cannot study on campus as often as they would like due to the time it takes to get to campus (see Figure 1).

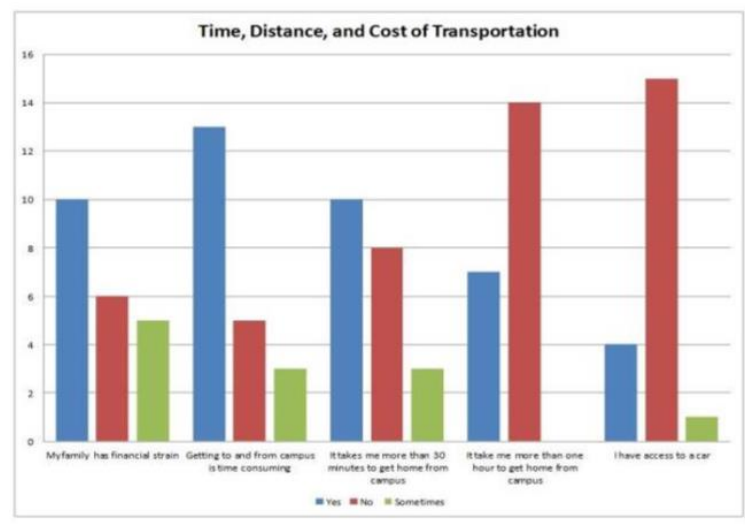

Figure 1. Time, distance, and cost of transportation commute to campus

Ten participants $(n=21,48 \%)$ ranked housing as the number one problem impacting their academic success. Six students $(\mathrm{n}=21,29 \%)$ ranked finances as the major problem, 3 students $(n=21,14 \%)$ prioritized transportation and 2 students $(n=21$, $10 \%$ ), emotional support. Because 17 participants $(\mathrm{n}=21,71 \%)$ reported having some degree of familial financial strain, the option to afford on-campus or even nearby off-campus housing is very limited. Sixteen participants $(\mathrm{n}=21,76 \%)$ stated getting to and from campus is time consuming, with 13 
participants $(n=21,62 \%)$ reporting the commute takes more than 30 minutes and for 7 students $(n=21$, $33 \%$ ), more than an hour to get from their home to campus. Fifteen students $(\mathrm{n}=20,75 \%)$ reported not having access to a vehicle, with 1 student $(n=20,5 \%)$ sometimes having that access. This would result in their reliance on public transportation. Figure 2 demonstrates the effects of living off campus with regards to informal and formal group study.

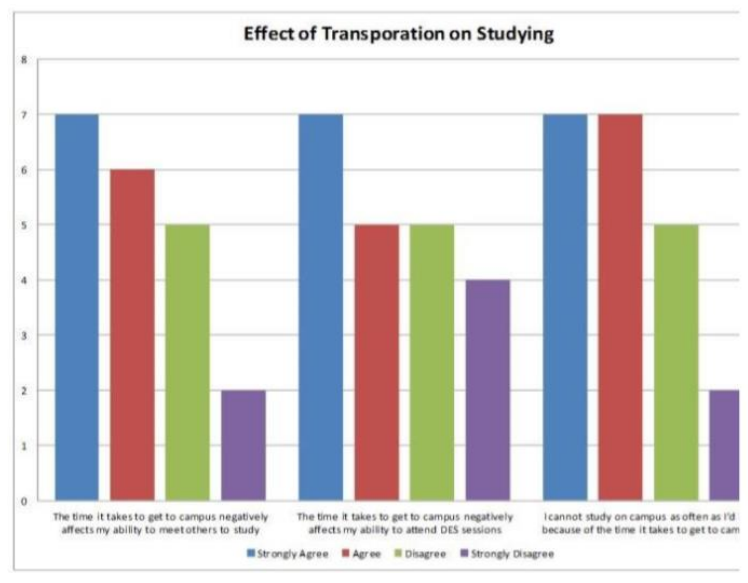

Figure 2. Effect of transportation on studying

\section{Discussion}

Of the five non-academic factors associated with academic performance [14], Grenadian SOM students responded favorably to mindset and perseverance. Nineteen students $(n=21,90 \%)$ agreed that they are as academically skilled and as prepared as the average applicant to SGU, which reflects a positive mindset. They demonstrated perseverance through their determination to complete the degree, with 15 participants $(n=23,65 \%)$ absolutely certain they would obtain a degree, exhibiting the important component of grit, which has been associated with academic success [15].

In response to the first research question, Grenadian SOM students identified several nonacademic challenges. A major issue identified by Jacobs [9] was support systems. In 2015, Grenadian medical students felt that they were well supported, both on- and off-campus. Indeed, the majority of participants reported having a strong support system and families that encourage their academic pursuits. This is significant since only $8 \quad(n=24,33 \%)$ students' mothers and $7(\mathrm{n}=24,29 \%)$ students' fathers held a bachelor's degree or higher. Thus, approximately $70 \%$ may be in the first generation of their families that graduate from university. Because parental education level is a predictor of student performance [17], student mindset and perseverance become more important. Grenadian medical students are also connected to their home communities away from the university community, with students identifying non-school related activities as valuable, including church, family obligations, sports, and volunteer work. This is important as structural factors affect these students' abilities to become fully integrated into the campus community. Students did not feel that these non-school related activities had a negative impact on their studies, with 15 students $(n=21,71 \%)$ responding that these activities did not make it challenging to find study time.

Grenadian SOM students felt that their nonacademic issues stemmed from much more structural restrictions: the inter-related challenges of housing, finances, and transportation. Ten students $(\mathrm{n}=21,48 \%)$ identified housing as the most significant nonacademic challenge they face. The government scholarship covers tuition charges for Grenadian medical students. The University provides housing subject to availability. While all foreign students are guaranteed on-campus housing in their first academic term at SGU, on-campus housing is still subject to availability for Grenadian students. SGU representatives report that most Grenadian SOM students who inquire about on-campus housing are accommodated, but the location and timeline varies. Grenadian SOM students might have to wait a few weeks into the academic term before moving into oncampus housing, depending on the changes and alterations made for foreign students' accommodation. This can increase anxiety in the first few weeks as it creates poor schedule structure for studying and increased travel time between their family's home and school. Grenadian SOM students who are successful with obtaining on-campus housing are actually placed in the Grand Anse campus, which is approximately a fifteen-minute bus ride away from the main campus located in True Blue. At the Grand Anse campus, there are no study groups or any designated study areas, which can be an unfortunate disadvantage to the Grenadian SOM students. They would have to factor in the various bus times and transportation between campus and their dormitories. This would take time away from their own studies and decrease their ability to study in quiet study halls rather than a crowded dormitory room with two other students.

Time management in medical school is a critical skill that all students must master in order to succeed, and the time it takes to get to campus directly relates to student success. Transportation is closely aligned with financial support and housing issues. Only four students $(n=20,20 \%)$ said they had access to a car. Therefore, transport to and from campus is on public buses. Transportation is a major concern for Grenadian SOM students for a number of reasons. SGU is off the main bus route. The SGU operated buses only have select routes in the school's vicinity. The national public bus system, the only form of organized public transportation on the island, is managed by private bus operators with nightly 
buses ceasing their last trip any time between 7:009:00pm, depending on the bus route, from the main bus terminus in St. George's, capital of Grenada. This caused a problem for students as some were unable to participate in formal and informal review groups due to transportation time and distance as well as a lack of late-night buses. Thirteen students $(n=20,65 \%)$ reported that travelling to campus limited their ability to meet for group study, and 12 students $(n=21,57 \%)$ said that this impacted their ability to attend DESfacilitated study sessions. The majority of Grenadian SOM students lived at home with their parents or guardians. Home villages ranged from a radius of 10 miles from SGU to much further rural villages in the outer parishes of Grenada. With travel times ranging from anywhere between twenty minutes to two hours, this nonacademic factor had a direct effect on students' academic performance as it significantly reduces time dedicated to studying. Additionally, the distance between home and school made it challenging for 14 $(\mathrm{n}=21,67 \%)$ students to study on campus as often as they would have liked. This is especially important because students also reported that their family homes lacked quiet study space. As well, two students lacked access to Internet at home. SGU places a significant portion of study materials online, including lecture and lab slides, handouts, notes, and recordings, as well as some quizzes. Without reliable access to the Internet, students are significantly disadvantaged.

These structural barriers to student success impacted Grenadian SOM students' ability to utilize the same learning strategies and academic behaviors available to students who live on campus or nearby. These students may have to rely more on individual study than group study, which has potential negative impacts to long term success [7]. Since students may lack quiet study space and Internet at home, the lack of transportation and distance from campus also impacted ability to study independently, highlighting the inter-connectivity between housing, finances, and transportation.

Finances are another interdependent, critical, nonacademic component. In fact, finances were frequently cited as a problem, with 6 students $(n=21$, $29 \%$ ) mentioning finances as the biggest nonacademic challenge in an open-ended response. Ten students $(n=21,48 \%)$ reported that housing was the most critical factor in their academic success. The financial strain may explain why housing was ranked as a critical factor since on-campus and offcampus housing is expensive. Students discussed the negative implications finances had on their housing; without adequate financial support, students could not live closer to campus.

Additionally, several students mentioned the high cost of on-campus food. The cost of living in Grenada has drastically increased since Jacob's study, specifically with cost of public transportation and cost of food. Even if Grenadian SOM students are granted on-campus housing, there is still a disconnect as to how the student would pay for food and living essentials. A student who lives at home does not have to factor in the variable of food cost or even access to food as it would be provided from home. A recent development, that did not affect our cohort, is that all students must now purchase renter's insurance, which will only add to the financial burden. A living stipend for Grenadian SOM students living on-campus would remarkably reduce this possible stressor.

Our second research question asked how the factors affecting student success at SGU have changed in the past 17 years. Our findings show that there has not been significant change in the factors affecting Grenadian medical students' success since Jacobs' study in 1999. Housing, finances, and transportation are still the most significant selfperceived barriers to student success. As the overall student population has grown, a housing shortage has developed which has affected all students requesting on-campus housing contracts, making Grenadian SOM students the last on the list to receive housing. The University is responding to this need for more oncampus housing with the building of a new dormitory and yet, SOM entering class sizes continue to increase each term. All incoming foreign Term 1 students are guaranteed on-campus housing their first term at SGU but for all subsequent terms, they must enter into a lottery system to apply for oncampus housing each term. This can be detrimental for Grenadian SOM students who acquired oncampus housing in their first term, as they have grown accustomed to resources available on campus, engagement in review groups, and peer studying. If they are not granted oncampus housing for their remaining terms, they would be forced to return to their family home and commute to campus, which defeats the whole rationale of them acquiring oncampus housing at the beginning of medical school.

Seventeen years ago, Jacobs [9] recommended improving the housing situation in order to alleviate unnecessary stress. We agree with this recommendation and recommend that Grenadian SOM students are guaranteed on-campus housing for their entire two years in Basic Sciences in Grenada. A positive structural change that has occurred in the past 17 years was the implementation of Jacobs' recommendation to install lockers on campus for all students to use. Grenadian students used to have a difficult time managing all their books, study materials, and clinical supplies, but now this problem is alleviated through access to lockers.

Our third research question asked what support is needed for Grenadian medical students at SGU. Based on the students' responses, we feel that the best way to support them is by expanding the 
government scholarship to include a small living allowance during their two years studying Basic Sciences at SGU, and SGU should provide guaranteed on-campus housing. This would alleviate the housing, financial, and transportation problems affecting their ability to study. There also seems to be a disconnect between the housing policy and students' perceptions reported in the survey. As stated previously, SGU representatives report that nearly all students who inquire about on-campus housing are placed in dormitories at the Grand Anse campus, depending on availability, yet students identified housing as their most challenging nonacademic issue. A possible explanation for this disconnects is that students are reluctant to apply for on-campus housing, because they feel it is unlikely they will get accommodation, due to the lottery system and high demand by foreign students. By establishing guaranteed on-campus housing, this would help alleviate housing as a nonacademic issue.

On-campus housing would limit the transportation issues Grenadian SOM students currently have, allowing them to participate fully in group study and DES-facilitated groups. A small living allowance should be provided to help with the financial costs of attending university. The living stipend would be crucial for offsetting increased cost of living when students move to campus. In particular, students living on campus instead of at home would have increased food costs. Additionally, students who opt out of living on campus could use the stipend to help cover Internet costs at home and bus fare, both of which were identified as challenges in the survey. All Grenadian medical students would benefit from a stipend allowing them to purchase food on campus, which several participants identified as being problematic. This is not unprecedented; many scholarships include housing and a living allowance. The financial cost to the government would be minimal because the number of students is so small.

The questionnaire survey for this study was dispersed in the Fall 2015 term, which coincidently, was the largest incoming SOM class SGU had ever experienced. Since foreign Term 1 students are guaranteed on-campus housing their first term of medical school, the housing department had to make appropriate adjustments for the massive number of students. The overflow of Term 1 students was placed at a local hotel for their first term, which was twenty minutes away via the SGU bus route. This variable plays a crucial role in our study, in that, with the influx of foreign SOM students, it drastically reduced the opportunity to house Grenadian SOM students.

The primary limitation of this study was the inherently biased, subjective nature of a self-report survey. Students reported their perception of academic preparedness and their perception of what impacts their studies, but there is no way to know how accurate students' self-perceptions are. One way to overcome this bias is to correlate student responses with objective academic performance. However, we chose to delimit our study to exclude grades in order to protect student anonymity. Thus we did not know which students completed the survey, and we could not correlate student responses with GPA.

Another limitation is the response rate and sample selection. 24 out of 36 of our population responded to the survey. While this $\mathrm{n}$ is not large, it represents $66 \%$ of the entire population of Grenadian SOM students. This is higher than the minimally acceptable response rate of $50 \%$ for social research [18]. Because our target population was so small, we used census sampling and invited our entire population to participate. This means that the sample was not random, so external validity is limited; however, the results could still be useful for other OMSs in the Caribbean and surrounding regions with local students comprising a small minority of the student population.

A third limitation is that this follow up study did not follow the same research design as Jacobs' original study [9]. Unlike the original study, which included both a survey and extensive interviews, we chose to delimit our study to only a survey. A survey took significantly less of the Grenadian medical students' time than an interview, and yet we still only had a $66 \%$ response rate. Requiring both a survey and an interview would have lowered our sample size so much as to make the results insignificant.

\section{Conclusion}

Grenadian SOM students felt that they were equally academically skilled and prepared for their studies as non-Grenadian SOM students. Research shows that feeling prepared positively impacts academic performance [19]. Grenadian students also reported that they were well-supported by their families, communities, and SGU faculty. Jacobs [9] found that such emotional support played an important role in determining student success.

Housing, finances, and transportation were the three main non-academic issues that all of the 24 respondents believed to be the most prevalent nonacademic obstacles that affected their academic success at this international medical school. The best way to support Grenadian students in the SOM is to expand the government scholarship to include guaranteed on-campus housing and a small living allowance. This would significantly alleviate all three structural non-academic barriers to these students' success. Due to the small number of Grenadian students in SGU's School of Medicine, these recommendations should be quite feasible and 
realistically sustainable. Our research concluded that SOM Grenadian students are not treated as fairly as foreign SOM students as housing, finances, and transportation issues continue to be non-academic issues that are affecting these students. Minor financial assistance and accommodation support from the university could allow these students to start their Basic Science curriculum at the same level as their foreign classmates.

Future research could focus on whether being a minority impacts student perception of learning. It would be interesting to compare student perception and student learning outcomes as measured by grades.

\section{Conflict of Interest}

The authors declare that they have no conflict of interest.

\section{References}

[1] Eckhert, N. L. (2010). Perspective: private schools of the Caribbean: outsourcing medical education. Academic Medicine, 85(4), 622-630.

[2] Eckhert, N. L., \& van Zanten, M. (2014). Overview of For-Profit Schools in the Caribbean. unknown: Foundation for Advancement of International Medical Education and Research. Retrieved from http://www.faimer.org/research/ faimer-short-reportcaribbean.pdf

[3] National Residency Match Program and Educational Commission for Foreign Medical Graduates. (n.d.). Charting outcomes in the match: International medical graduates. Washington, DC. Retrieved from http://www.ecfmg.org/resources/NR MP-ECFMGCharting-Outcomes-in-the-MatchInternationalMedical-Graduates-2014.pdf

[4] St. George's University, (2016). History of SGU. Retrieved from http://www.sgu.edu/aboutsgu/historyof-sgu.html

[5] Ross, M. T., \& Cameron, H. S., (2007). Peer assisted learning: a planning and implementation framework: AMEE Guide no. 30. Medical Teacher, 29(6), 527-545.

[6] Santee, J., \& Garavalia, L., (2006). Peer tutoring programs in health professions schools. American Journal of Pharmaceutical Education, 70(3), W1.

[7] Meo, S. A. (2013). Basic steps in establishing effective small group teaching sessions in medical schools. Retrieved from http://www.pjms.com.pk/ index.php/pjms/article/view/ 3609.
[8] United Nations Statistics Division. (2016). UN data country profile Grenada. Retrieved from http://data.un.org/CountryProfile.aspx $? \mathrm{crName}=\mathrm{gren}$ a da

[9] Jacobs, G., (1999). The identification and analysis of the unique non-cognitive factors that are related to the successful academic performance of indigenous Grenadian students who matriculate into medical programs of St. George's University. dissertation, Port Elizabeth, South Africa.

[10] Tam, M., (2002). University impact on student growth: a quality measure? Journal of Higher Education Policy and Management, 24(2), 211-218. https://doi.org/10.1080/1360080022000013527

[11] Tracey, T. J., \& Sedlacek, W. E., (1982). NonCognitive Variables in Predicting Academic Success by Race. Presented at the Annual Meeting of the AMerican Educational Research Association, New York, NY, USA. Retrieved from http://eric.ed.gov/ ?id=ED219012.

[12] Tracey, T., \& Sedlacek, W. E. (1990, December). Supplementary Admissions Questionnaire II. Retrieved from http://williamsedlacek.info/ publications/surveys/unive rsityofmaryland.html.

[13] Thomas, L. L., Kuncel, N. R., \& Credé, M. (2007). Noncognitive Variables in College Admissions The Case of the Non-Cognitive Questionnaire. Educational and Psychological Measurement, 67(4), 635-657.

[14] Nagaoka, J., Farrington, C. A., Roderick, M., Allensworth, E., Keyes, T. S., Johnson, D. W., \& Beechum, N. O., (2013). Readiness for College: The Role of Noncognitive Factors and Context. Voices in Urban Education, 38, 45-52.

[15] Duckworth, A. L., Peterson, C., Matthews, M. D., \& Kelly, D. R., (2007). Grit: perseverance and passion for long-term goals. Journal of Personality and Social Psychology, 92(6), 1087.

[16] Hayes, A. L., Mansour, N., \& Fisher, R., (2015). Understanding intercultural transitions of medical students. International Journal of Medical Education, 6,26 .

[17] Win, R., \& Miller, P. W., (2005). The effects of individual and school factors on university students' academic performance. Australian Economic Review, 38(1), 1-18.

[18] Richardson, J. T. E., (2005). Instruments for obtaining student feedback: a review of the literature. 
Assessment \& Evaluation in Higher Education, 30(4), 387-415. https://doi.org/10.1080/0260293050 0099193

[19] Duque, L. C., \& Weeks, J. R. (2010). Towards a model and methodology for assessing student learning outcomes and satisfaction. Quality Assurance in Education, 18(2), 84-105. https://doi.org/http://dx.doi.org.ezp.waldenulibrary.o r g/10.1108/09684881011035321. 